\title{
The Midas cichlid species complex: incipient sympatric speciation in Nicaraguan cichlid fishes?
}

\author{
MARTA BARLUENGA and AXEL MEYER \\ Department of Biology, University of Konstanz, Universitätsstrasse 10, 78457 Konstanz, Germany
}

\begin{abstract}
Sympatric speciation is a contentious concept, although theoretical models as well as empirical evidence support its relevance in evolutionary biology. The Midas cichlid species complex (Amphilophus citrinellus, labiatus, zaliosus) from several crater lakes in Nicaragua fits several of the key characteristics of a sympatric speciation model. In particular, in $A$. citrinellus (i) strong assortative mating on the basis of colour polymorphism and (ii) ecological differentiation based on morphological polymorphisms involving the feeding apparatus and body shape might both be mechanisms of incipient speciation. Seven microsatellite markers and mtDNA control region sequences [ 836 base pairs (bp)] were used to study the population genetic structure of 519 specimens of Midas cichlid populations from the two Great Lakes Managua and Nicaragua, and three crater lakes in Nicaragua, Central America. The three named species of the species complex occupy different ecological niches, are morphologically distinct and can be distinguished genetically. We uncovered allopatric genetic differentiation of populations of $A$. citrinellus from different lakes and distant locations within Lake Managua and, more interestingly, incipient genetic differentiation of several sympatric populations based on colouration (in A. citrinellus and A. labiatus) but not on the morphology of the pharyngeal jaws (in A. citrinellus). Sexual selection and assortative mating might be the driven forces of diversification within named species. The Midas cichlid species complex in Nicaragua is an excellent model system for the study of the incipient stages of adaptation, speciation and the formation of species flocks.
\end{abstract}

Keywords: Amphilophus spp. crater lakes, ecological specialization, parallel speciation, sexual selection, sympatric speciation

Received 29 November 2003; revision received 12 February 2004; accepted 19 March 2004

\section{Introduction}

The relative importance of alternative mechanisms that generate and shape organismal diversity continues to be debated vigorously (e.g. Schluter 2000; Losos et al. 2003). It is believed that most species evolved in allopatry by divergence of geographically isolated populations from an ancestral species (Mayr 1963). Speciation in the absence of geographical barriers has often been dismissed by the argument that continuous gene flow would prevent the establishment of fixed genetic differences which would be necessary for the formation of species. However, a growing body of empirical data shows that closely related species

Correspondence: Axel Meyer. Fax: +49 7531883018; E-mail: axel.meyer@uni-konstanz.de often occur in sympatry (e.g. Meyer et al. 1990; Schluter 1994; Feder 1998; Barraclough \& Vogler 2000; Via 2001; Seehausen et al. 2003; Verheyen et al. 2003). Also, theoretical approaches have identified a variety of evolutionary processes and conditions that can result in speciation under sympatric conditions (Dieckmann \& Doebeli 1999; Kondrashov \& Kondrashov 1999; Doebeli \& Dieckmann 2000; Gavrilets \& Waxman 2002). Natural selection through ecological specialization to local environments is accepted as the main cause of divergence in sympatric populations (Kondrashov et al. 1998; Schluter 2000). However, sexual selection through assortative mating has been proposed as another mechanism promoting divergence in sympatry (Higashi et al. 1999; Wilson et al. 2000; Van Doorn et al. 2001; Gavrilets \& Waxman 2002).

Cichlid fishes (Family Cichlidae) are one of the best model systems for the study of biological diversification 
(e.g. Meyer et al. 1990; Kornfield \& Smith 2000). They are distinguished through enormous richness of species, great diversity of trophic adaptations and behaviours and the extreme rapidity of their divergence (reviewed in e.g. Fryer \& Iles 1972; Meyer 1993a; Stiassny \& Meyer 1999). All these features make cichlids premier examples of rapid speciation. Time spans associated with the diversification of many of these species assemblages are extremely short (e.g. Meyer et al. 1990; Verheyen et al. 2003). Much effort during the last decades has been devoted to the question of which evolutionary processes might explain most effectively the evolutionary success of these fishes (Liem 1973). The greatest diversity of cichlids is found in lacustrine environments in East Africa, where they form large, often monophyletic, species flocks of up to several hundred endemic species (Meyer et al. 1990; Salzburger et al. 2002; Seehausen et al. 2003; Verheyen et al. 2003). It is debated, however, to what extent the dominant mode of speciation in the Great Lakes of East Africa was sympatric (e.g. Turner \& Burrows 1995). Some theoretical models suggest that sympatric speciation may happen more rapidly than allopatric speciation (Dieckmann \& Doebeli 1999), which is consistent with the extremely young age of some of the adaptive radiations of cichlids of the African Great Lakes.

Cichlids are renowned for their vast diversity of trophic morphologies and often extreme degree of ecological specialization (e.g. Hori 1993; Schliewen et al. 1994; Rossiter 1995; Sturmbauer 1998; Huysseune et al. 1999; Rüber et al. 1999; Stiassny \& Meyer 1999). However, the sympatric occurrence of many sibling species that seem to differ only in colouration makes it unlikely that ecological specialization is the sole mechanism of speciation in this group (Seehausen et al. 1997; Kornfield \& Smith 2000; Baric et al. 2002). The role of colouration differences and sexual selection is considered central to diversification in cichlids by some authors (Meyer 1993a; Seehausen et al. 1997; Knight \& Turner 1999; Seehausen \& van Alphen 1999; Wilson et al. 2000). That sexual selection operates in cichlid fishes had already been suggested previously in the study of the group (Kosswig 1947), but critical empirical support is still limited. Clearly, a single mechanism will be insufficient to explain the origin of all cichlids, and the relative importance of various alternative mechanisms of speciation is likely to vary between the different species flocks (reviewed in, e.g. Kornfield \& Smith 2000; Danley \& Kocher 2002; Streelman \& Danley 2003).

With three described species, the Neotropical Midas cichlid species complex is a simple model of a cichlid radiation that may contribute to the understanding of the relative importance of alternative evolutionary processes in the generation of cichlid diversity. The species of the Midas cichlid complex are distributed in the Great Lakes of Nicaragua as well as in several crater lakes in the area (Fig. 1). Combined, they represent by far the largest biomass of any fish species in Nicaraguan freshwaters and are an important food source for the human population of Nicaragua (Barlow 1976; Barlow \& Munsey 1976). Neotropical cichlid assemblages are typically less species-rich than in African lakes. The Midas cichlid species complex is one of the few examples among Neotropical cichlids with an almost exclusively lacustrine distribution, resembling the predominant evolutionary scenario of the African cichlid species flocks. Nevertheless, this group of cichlids is extremely variable in morphology, behaviour and ecology (Lowe-McConnell 1991). Endemism and local specialization are also quite common and to some extent Neotropical cichlids replicate the African lacustrine evolutionary scenario, albeit at a smaller scale (Stiassny 1981).

Barlow \& Munsey (1976) recognized three different species within the Midas cichlid complex: Amphilophus citrinellus (Günter), the Midas cichlid, a generalist species with very widespread distribution, A. labiatus (Günter), the red devil cichlid, a fleshy-lipped species thought to be restricted to the big lakes L. Nicaragua and L. Managua, and $A$. zaliosus (Barlow), the arrow cichlid, an elongated species that is restricted in its distribution to one of the crater lakes, L. Apoyo (Fig. 2). Recent studies claim that more species might exist in some of the crater lakes, although genetic data in support of these largely phenotypic descriptions are still not available (McKaye et al. 2002; Stauffer \& McKaye 2002).

The Midas cichlid complex is highly polymorphic. Within A. citrinellus and A. labiatus a polychromatism has been described (Fig. 2), with a cryptic form, grey or brown with dark bars or spots (normal morph) and a conspicuous form, which lacks melanophores, resulting in brightly red, orange, or yellowish coloured fish (gold morph). All A. zaliosus have the cryptic colouration (Barlow 1976). Strong (95\% of the pairs have the same colouration) assortative mating according to colour has been observed in A. citrinellus both in the field and in captivity (Barlow 1976; McKaye \& Barlow 1976), suggesting that sexual selection maintains the colour polymorphism (McKaye 1980). Genetic differentiation between the two colour morphs has already been documented in some populations of $A$. citrinellus (Wilson et al. 2000).

Cichlid fishes are characterized by a second pair of jaws in the pharyngeal area in addition to the oral jaws, and this key innovation (Liem 1973) is presumed to be responsible for their great ability to colonize new habitats and to exploit successfully a large diversity of trophic niches (Liem 1973). For A. citrinellus two types of pharyngeal jaws have been described (Fig. 2), a papilliform morph with slender pointed teeth feeding on soft prey and a molariform morph with thicker rounded teeth feeding on hard prey - only papilliform pharyngeal jaws have been documented in A. labiatus and A. zaliosus (Meyer 1989; 1990ab). Previous performance studies (Meyer 1989) showed that there is a 


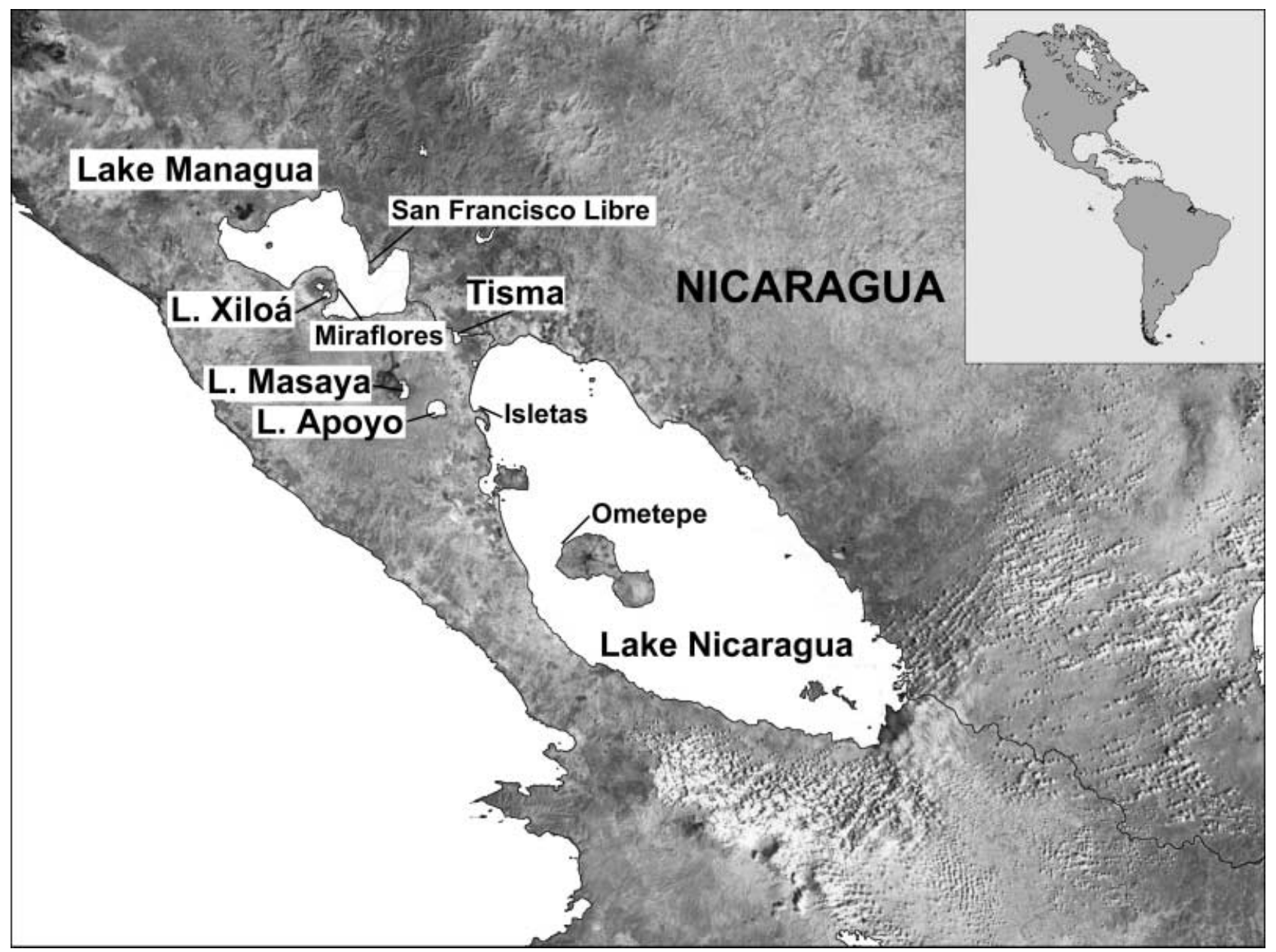

Fig. 1 Map of the area of the Nicaraguan Great Lakes showing the sampling localities.
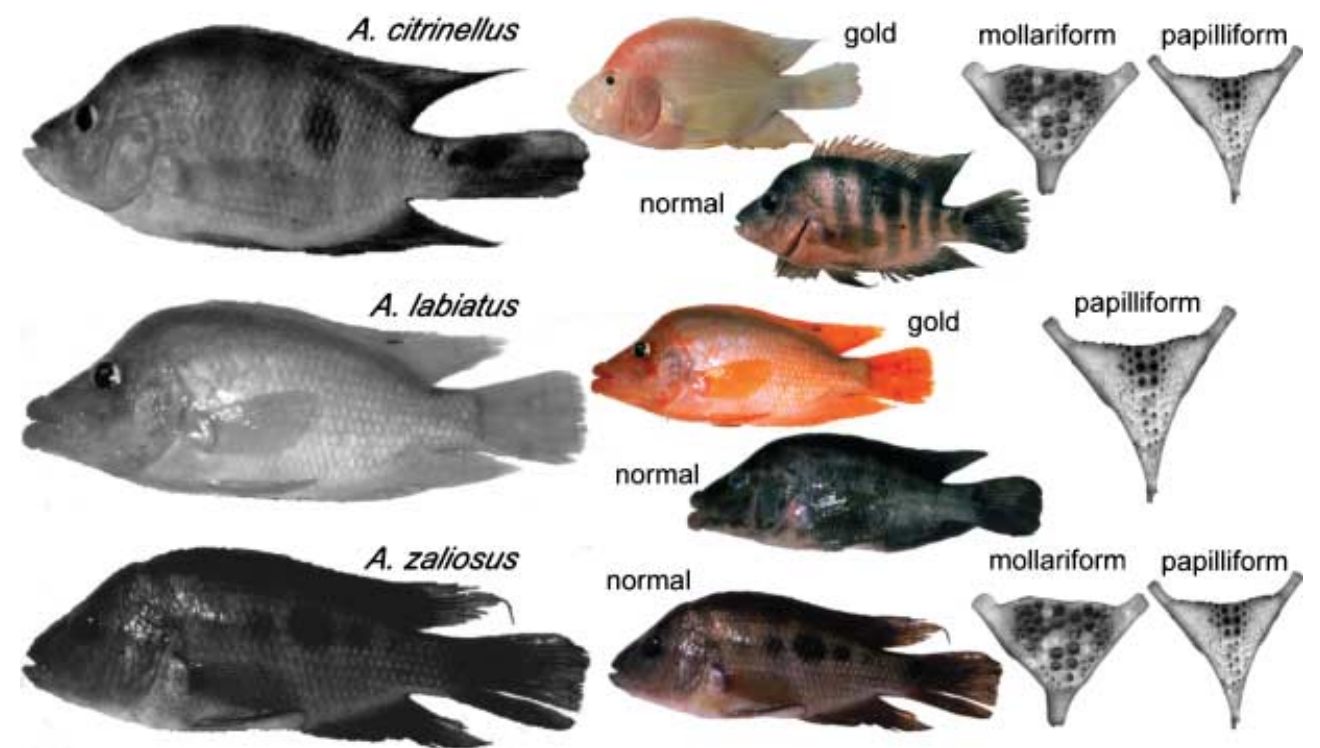

Fig. 2 Specimens of the three described species of the Midas cichlid species complex. A. citrinellus and A. labiatus are polychromatic with gold and normal individuals, and A. citrinellus and A. zaliosus are trophically polymorphic with papilliform and molariform pharyngeal jaws. 
trade-off in performance: the molariform fish are specialized and more efficient at eating hard diets such as snails, whereas they are less efficient in feeding on soft diets than the papilliform morphs and vice versa. These two ecological forms might be in the process of speciation through ecological speciation and the trophic polymorphism might be maintained by disruptive natural selection, selecting against intermediate phenotypes and promoting reproductive isolation between them (Meyer 1989, 1990a,b, 1993b).

By being polychromatic as well as trophically polymorphic, the Midas cichlid species complex fits well the prerequisites for both natural and sexual selection to be promoting divergence of populations under sympatric conditions. Both types of speciation mechanisms through sexual selection as well as through ecological speciation might be acting in concert or successively. In an initial study on the relative importance of sexual selection based on female choice for mates with a particular colour and ecological speciation due to polymorphism in the pharyngeal jaws (Wilson et al. 2000), the authors concluded that sexual selective forces might be faster and/or earlier in A. citrinellus than ecological speciation through the trophic polymorphism in the pharyngeal jaw. Furthermore, Wilson et al. (2000) found that not only traditional allopatric speciation mechanisms might be acting in the big Nicaraguan lakes, relatively old and large, offering sufficient geographical structure for the existence of barriers to gene flow. Most interestingly, their analyses suggested that even within crater lakes that clearly do not provide any geographical structure, none the less genetic differential was found based on colouration but not based on trophic/ ecological traits. Because both the colour and trophic polymorphisms are present in several of the crater lakes, and because these lakes are fully distinct from each other genetically (Wilson et al. 2000) they might, similar to the situation in the post-Pleistocene lakes of British Columbia, serve as examples for repeated speciation of similar species in parallel (Kirkpatrick 2000). The results of this first population genetic study on the polychromatic and polymorphic $A$. citrinellus suggested that it is an example for incipient speciation in sympatry and parallel evolution (Kirkpatrick 2000; Wilson et al. 2000).

The initial genetic study on A. citrinellus was based on a relatively small sample (141 individuals collected in 1987 from four lakes; this study is based on 519 samples collected in 2001 from six lakes and eight localities) and was restricted to this species; here we also included samples from the other described species of the Midas cichlid complex (A. labiatus and A. zaliosus). The first genetic study used fewer microsatellite markers (four vs. seven) and a shorter fragment [ 480 base pairs (bp) vs. $836 \mathrm{bp}$ ] of the mitochondrial control region than the present study. During the last 15 years, since the collection of the samples for the first study (McCrary et al. 2001) some drastic ecological changes are said to have occurred, in particular in the crater Lake Apoyo, due to the introduction of non-native African tilapiine cichlid fishes.

This study aims to test the generality of the prime role of assortative mating through colour preference with respect to ecological speciation based on ecologically relevant morphological traits, such as pharyngeal jaw morph and body shape, in the Midas cichlid species complex.

\section{Materials and methods}

\section{Sample collection}

Specimens of the Midas cichlid complex were collected during the dry season (February-March) of 2001 from the Great Nicaraguan Lakes, Lake Managua (two locations: Miraflores, San Francisco Libre: S. Fco Libre) and L. Nicaragua (two locations: Isletas, Ometepe) from Tisma pond at the Tipitapa River that connects both lakes, and from three crater lakes, L. Xiloá, L. Apoyo and L. Masaya (Fig. 1), covering the main area of distribution of this species. A total of 519 individuals were collected (Table 1). Fish were collected with gill nets and photographed in the field for further morphometric analyses (see Klingenberg et al. 2003). Pharyngeal jaws from all specimens were dissected and fish were preserved in $80 \%$ ethanol for

\begin{tabular}{|c|c|c|c|c|c|}
\hline \multirow[b]{2}{*}{ Species } & \multirow[b]{2}{*}{ Location } & \multicolumn{2}{|c|}{ Papilliform jaws } & \multicolumn{2}{|c|}{ Molariform jaws } \\
\hline & & Normal & Gold & Normal & Gold \\
\hline \multirow[t]{7}{*}{ A. citrinellus } & L. Managua, Miraflores & 31 & 25 & 3 & 1 \\
\hline & L. Managua, S. Fco Libre & 64 & 38 & 1 & 1 \\
\hline & Tisma Pond & 21 & 24 & 1 & - \\
\hline & L. Nicaragua, Ometepe & - & - & 32 & 2 \\
\hline & L. Nicaragua, Isletas & 13 & 3 & 25 & 17 \\
\hline & Lake Xiloa & 7 & - & 18 & - \\
\hline & Lake Masaya & 35 & 1 & - & - \\
\hline A. labiatus & L. Nicaragua, Isletas & 38 & 69 & - & - \\
\hline A. zaliosus & Lake Apoyo & 41 & - & 8 & - \\
\hline
\end{tabular}

Table 1 Sample sizes of the different species and locations by colour and trophic morphs 
laboratory analyses. All fish were identified as A. citrinellus, A. labiatus or A. zaliosus based on the taxonomic description by Barlow \& Munsey (1976). All specimens of A. labiatus were caught in Isletas in L. Nicaragua, and all specimens of A. zaliosus were caught in L. Apoyo (the only place where they exist). All individuals captured in L. Apoyo were identified as A. zaliosus based on their elongated body (see Klingenberg et al. 2003). All fish were scored for their colouration (normal morph, grey or brown with dark bars or spots vs. gold morph, brightly coloured, red, orange or yellowish; Barlow 1976) and pharyngeal jaw type (papilliform morph with slender pointed teeth associated with soft food vs. molariform morph with thicker rounded teeth and hypertrophied musculature associated with a diet of hard food items (Meyer 1989, 1990a,b) (Fig. 2).

\section{mtDNA amplification and sequencing}

Total DNA was isolated using a proteinase $\mathrm{K}$ digestion followed by sodium chloride extraction and ethanol precipitation (Bruford et al. 1998). The complete mitochondrial control region (836 bp) was amplified using published primers and polymerase chain reaction (PCR) conditions (Kocher et al. 1989; Meyer et al. 1994) with a GeneAmp PCR System 9700 Thermocyler (Applied Biosystems). The PCR products were purified using the QIAquick PCR purification kit (Qiagen), and sequenced in both directions with the BigDye Terminator Cycle Sequencing Ready Reaction kit (Applied Biosystems). Sequencing products were analysed on an ABI 3100 Automated Sequencer (Applied Biosystems). The mtDNA sequences of this study have been deposited in GenBank under Accession nos AY567011AY567470.

\section{Microsatellite analysis}

In addition, seven nuclear DNA microsatellite loci were genotyped (Acit1, Acit2, Acit3, Acit4 Acit6, Noack et al. 2000; TmoM7, Zardoya et al. 1996; UNH002, Kellog et al. 1995). Microsatellites were amplified with fluorescent reverse primers (FAM and HEX dyes) and fragment length was analysed with the internal size marker GENESCAN500 ROX (Applied Biosystems) on an ABI 3100 Automated Sequencer (Applied Biosystems), and with the GENOTYPER version 3.7 (Applied Biosystems) software package.

\section{Phylogenetic and statistical analyses}

$m t D N A$ control region. Mitochondrial DNA sequences were aligned by eye and different haplotypes were identified with COLLAPSE version 1.1 (Posada 1999). All haplotypes found in the six lakes and the three species were plotted on an unrooted minimum spanning haplotype network according to the optimal tree obtained from a maximum likelihood analysis in PAUP* version 4.0b10 (Swofford 2002) that was translated into maximum parsimony branch lengths. A total of 10 homoplastic positions $(60,105,175,191,237$, $276,412,592,611,612,726)$ with a consistency index lower than 0.20, were removed from this analysis (Fig. 3). A sequence evolution model was chosen using a nested series of likelihood ratio tests (Huelsenbeck \& Crandall 1997) applying MODELtest 3.06 (Posada \& Crandall 1998) incorporated into PAUP*.

A mismatch analysis was performed to study the demographic history of species and populations (Fig. 4 and Table 2). The observed pairwise mismatch distributions were fitted to a sudden demographic model (stepwise expansion model)

Table 2 Mismatch analysis parameters. $\tau$ is the expansion parameter (in parentheses the 95\% confidence intervals); $\theta_{0}$ and $\theta_{1}$ are the substitution rates before and after the expansion, respectively; SSD is the test of the validity of a stepwise expansion model based on the sum of square deviations between the observed and the expected mismatch, and the significance of the test is estimated with a parametric bootstrap approach, and the same method is used to test the significance of the Raggedness index (probability values: ${ }^{*} P<0.05$, ${ }^{* *} P<0.001$, $\mathrm{ns}=$ nonsignificant $)$. The timing of the most important expansion in each group ( $\left.t_{\text {divergence }}\right)$ was calculated on the basis of the equation $\tau=2 \mu t$, where $t$ is the expansion time and $\mu$ the mutation rate ( $\mu$ was estimated form the dated origin of the crater L. Apoyo based on geological data)

\begin{tabular}{|c|c|c|c|c|c|c|c|}
\hline & $\begin{array}{l}\text { Mean no. of } \\
\text { differences }\end{array}$ & $\tau$ & $\theta_{0}$ & $\theta_{1}$ & SSD & $\begin{array}{l}\text { Raggedness } \\
\text { index }\end{array}$ & $t_{\text {divergence }}$ (year) \\
\hline \multicolumn{8}{|l|}{ A. citrinellus } \\
\hline L. Managua & 4.647 & $6.44(2.37-11.56)$ & 0.20 & 34.26 & $0.013^{\mathrm{ns}}$ & $0.029 \mathrm{~ns}$ & 91347 (33 617-163 972) \\
\hline Tisma Pond & 3.464 & $7.32(2.79-13.36)$ & 0.50 & 9.82 & $0.056^{\mathrm{ns}}$ & $0.129^{n s}$ & \\
\hline L. Nicaragua & 4.393 & $5.22(1.51-11.04)$ & 0.38 & 218.01 & $0.006^{\mathrm{ns}}$ & $0.023^{\mathrm{ns}}$ & 74043 (21 418-156 595) \\
\hline L. Xiloá & 2.439 & $4.65(1.32-9.31)$ & 0.20 & 95.44 & $0.099 \mathrm{~ns}$ & 0.269 ns & 65958 (18 723-132 057) \\
\hline L. Masaya & 2.968 & $3.57(1.35-6.40)$ & 0.09 & 973.99 & $0.097^{*}$ & $0.245^{*}$ & \\
\hline \multicolumn{8}{|l|}{ A. labiatus } \\
\hline L. Nicaragua & 4.530 & $4.91(1.65-9.93)$ & 0.48 & 451.52 & $0.007 \mathrm{~ns}$ & $0.024^{\mathrm{ns}}$ & 69645 (23 404-140 851) \\
\hline \multicolumn{8}{|l|}{ A. zaliosus } \\
\hline L. Apoyo & 1.207 & $1.41(0.28-3.16)$ & 0.09 & 1640.01 & $0.002^{\mathrm{ns}}$ & $0.039 \mathrm{~ns}$ & $20000(3971-44$ 823) \\
\hline
\end{tabular}




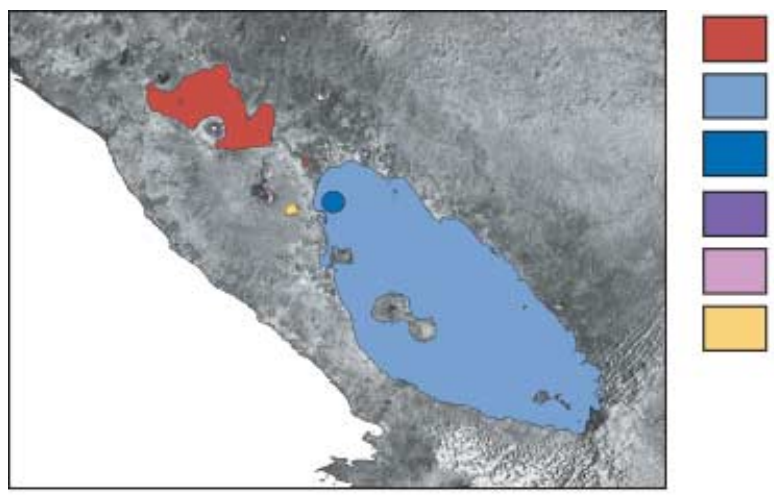

Lake Managua - Tisma (A. citrinellus)

Lake Nicaragua ( $A$. citrinellus)

Lake Nicaragua ( $A$. labiatus)

Lake Xiloá (A. citrinellus)

Lake Masaya (A. citrinellus)

Lake Apoyo (A. zaliosus)

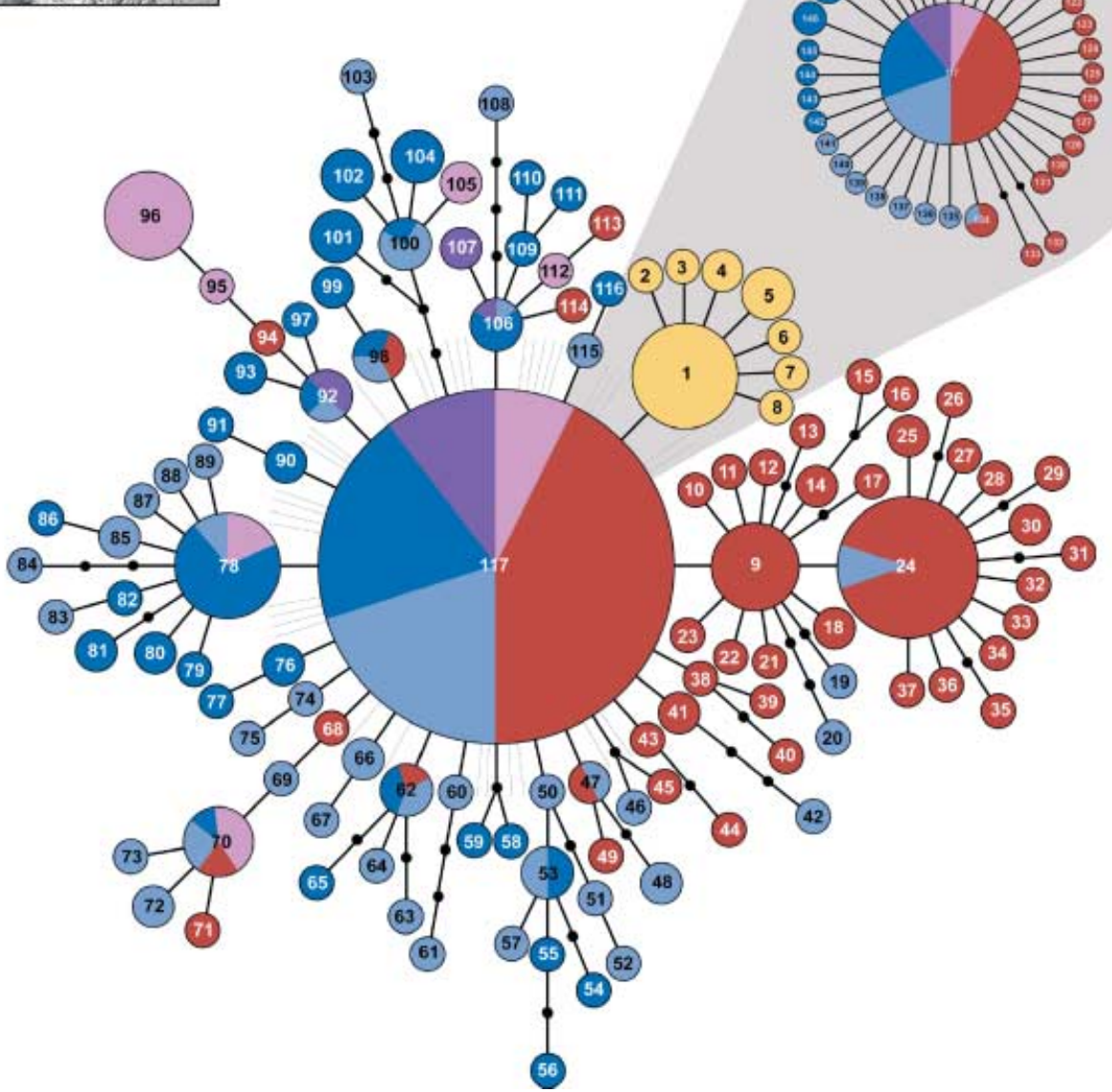

Fig. 3 Unrooted haplotype networks of the mtDNA control region showing the geographical distribution of haplotypes. Both networks represent the same central haplotype (117), the main network showing complex branches associated to the main haplotype and the network in the grey area showing one- and two-step single haplotypes connected to the central haplotype. The size of the circles resembles the number of individuals per haplotype, and the colour reflects the different species and localities.

by a generalized least square procedure following Schneider \& Excoffier (1999) as implemented in ARLEQUIN version 2.1 (Schneider et al. 2000). The validity of a stepwise expansion model for the data was tested by Monte Carlo Markov chain simulations (1000 steps) with ARLEQUIN. The moment estimator of time to the expansion $(\tau)$ was computed, and the time of the main expansion in generations $(t)$ was estimated from the equation $\tau=2 \mu t$, where $\mu$ is the mutation rate. The mutation rate was estimated from the calibration of the molecular divergence calculated with ARLEQUIN of the population in L. Apoyo for which dated geological information exists (Riedel 1972; Bice 1985) and compared with the existing molecular clock for control region in cichlids (Sturmbauer et al. 2001). We assumed a conservative estimate of a generation time of 2 years, although in the laboratory these fish become sexually mature at less than 1 year.

Genetic differences between named species, populations from different geographical areas and between sympatric 

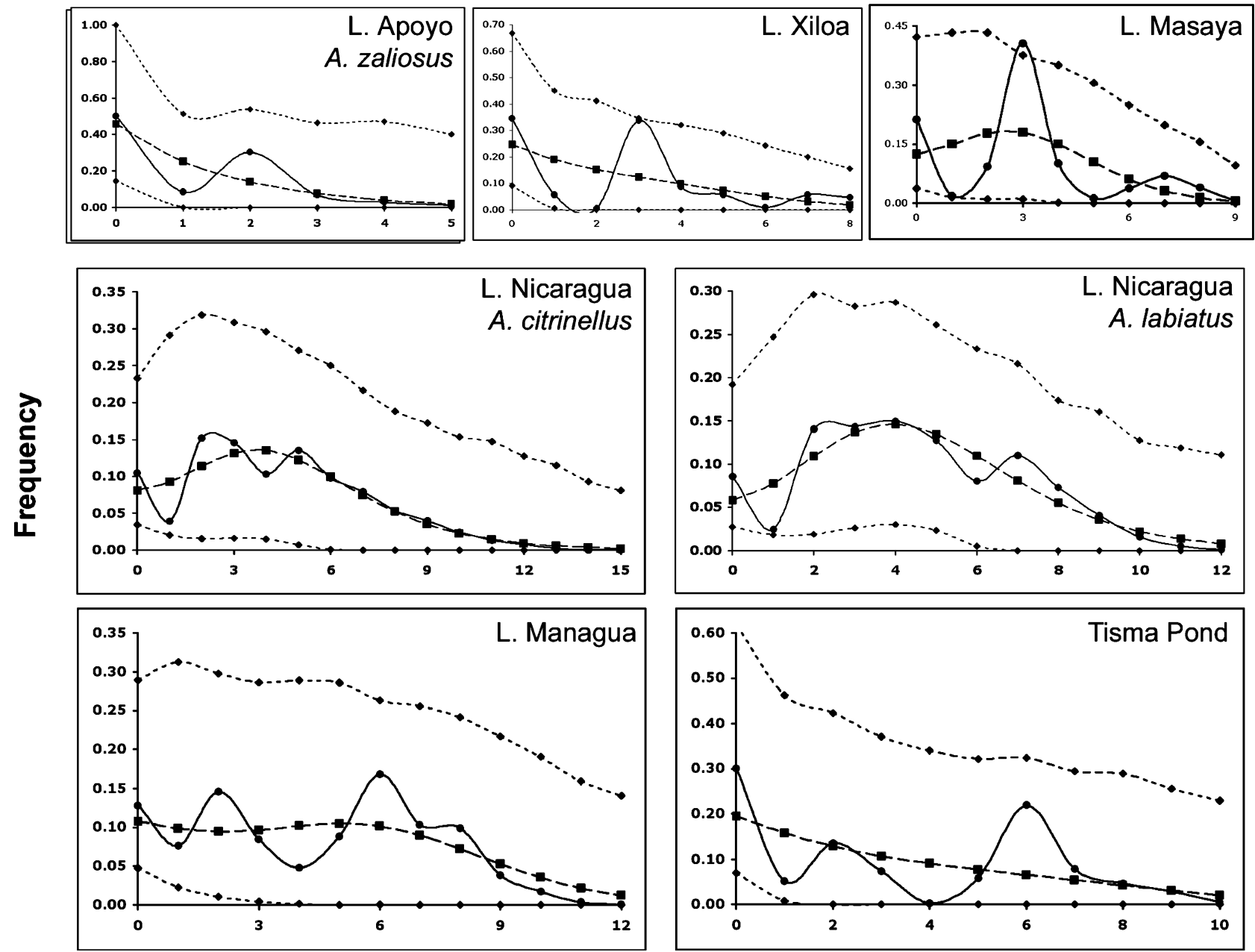

\section{Number of pairwise differences}

Fig. 4 Frequency distribution of pairwise number of mutational differences in mtDNA between individuals in the Midas cichlid complex. Each lake was analysed separately, and A. labiatus was analysed separated from A. citrinellus in L. Nicaragua. The dark curve represents the observed values, the dash curve with squares the model fitted to the data, and the dashed upper and lower curves the lower and upper boundaries (2.5-97.5 percentile values; 1000 simulations).

colour and jaw morphs were estimated with F-statistics (Weir \& Cockerham 1984) as calculated by ARLEQUIN.

Microsatellites. Departure from Hardy-Weinberg expectations for each locus across and within populations was calculated using a test analogous to Fisher's exact tests (Guo \& Thompson 1992) estimated with a 100000 step, 1000 iteration, Monte Carlo Markov chain series of permutations, as implemented in ARLEQUIN. Linkage disequilibrium for pairs of loci was tested for all possible pairs of loci in each population and globally for each pair of loci across populations with ARLEQUIN.

The genetic structure of named species, geographical areas and morphs was analysed by both Wright's Fstatistics (Weir \& Cockerham 1984) based on differences in allele frequencies, and $R_{\mathrm{ST}}$-statistics (Slatkin 1995) and based on differences in allele sizes, as implemented in ARLEQUIN. Two different statistics based on different mutation models were used due to the proven drawbacks of all existing models of microsatellite mutation and its relationship with migration (Balloux \& Lugon-Moulin 2002).

Critical significance levels for multiple testing were corrected following the sequential Bonferroni procedure (Rice 1989).

\section{Results}

Descriptive statistics, Hardy-Weinberg equilibrium and linkage disequilibrium

The seven microsatellite loci analysed detected high levels of polymorphism in the species studied (from three 
to 33 alleles). Disequilibrium between pairs of loci was nonsignificant in every comparison $(P>0.05)$. Tests for deviations from Hardy-Weinberg equilibrium within populations found no significant heterozygote deficit in all cases $(P>0.05)$ but one locus was deviating from equilibrium in the Tisma Pond population $(P<0.05$; Acit 2$)$.

\section{Haplotype network based on mtDNA sequences}

Among all individuals of the Midas-red devil-arrow cichlid species complex of this study we obtained 460 sequences and 154 different mtDNA haplotypes were found. The optimal model of molecular evolution found by MODELTEST was the transversional model with a gamma substitution correction (0.97) and a proportion of invariable sites of $0.60 \%$ (TVM + I + G).

A minimum spanning haplotype network was constructed (Fig. 3). The network obtained had a star-like structure, with the most abundant haplotype in the central position, including individuals from all localities except for L. Apoyo. Clusters of haplotypes arising from the main haplotype reflect the geographical differentiation of the populations within the species complex. A. zaliosus shared no haplotype with any of the other species, but $A$. citrinellus and A. labiatus shared several haplotypes.

\section{Molecular clock calibration and mismatch analyses}

We applied a molecular clock to estimate the divergence time of the lineages of the Midas cichlid, although we recognize the potential problems and limits associated with a molecular clock approach (see e.g. Page \& Holmes 1998). Therefore, the divergence times obtained are presented here only as an approximation.

A molecular clock was estimated through the calibration of the molecular divergence of the mtDNA sequences for the population of A.zaliosus, which originated in L. Apoyo during less than the approximate geological age of the lake of 23000 years (Riedel 1972; Bice 1985). The mean number of pairwise differences among all individuals of the Midas cichlid species complex sampled here based on the sequences whole control region (836 bp) was 1.135 (standard deviation 0.76 ), and the mutation rate obtained was $5.90 \%$ per site per Myr (1.95-9.86\%). In order to make our results comparable to previous molecular clocks estimated for African cichlids (Sturmbauer et al. 2001; Verheyen et al. 2003) we calculated the mutation rate considering only the most variable section of the control region (the first $365 \mathrm{bp}$ ). This estimate resulted in a mean number of pairwise differences of $0.594 \pm 0.49$ and an estimated rate of mutation of $7.08 \%$ per site per Myr (1.24\%-12.91\%). Previous estimations of the rate of mutation for this section of the control region for L. Malawi cichlids ranged from $6.5 \%$ to $8.8 \%$ per Myr (Sturmbauer et al. 2001), a value that is similar to our own results, corroborating the much higher rate of mutation of cichlid fishes compared to other groups of fishes (e.g. Donaldson \& Wilson 1999; Zardoya \& Doadrio 1999).

A mismatch analysis was performed to compare the demographic history of the different lineages of the Midas cichlid complex. The mismatch distribution differed substantially among populations from the different lakes (Fig. 4; Table 2). The crater lakes had a lower mean number of differences than the larger lakes in correspondence with the much younger age of these populations and the habitat they inhabit. The sample of A. zaliosus from L. Apoyo had the lowest mean number of differences (1.207), in agreement with the age of this crater lake based on geological data. The highest mean number of differences was found in the large and old L. Managua (4.689) where two modes were observed, suggesting population substructuring within the lake. Two modes are also observed in Tisma. Both A. citrinellus and A. labiatus in L. Nicaragua showed similar unimodal distributions, supporting the idea of a common relatively recent history. A model of sudden demographic expansion was supported for all populations except for the sample from L. Masaya. The time estimates of the most important demographic expansion in each group were calculated using the mutation rate obtained for the whole control region (Table 2). Time estimates were not calculated on the populations from L. Masaya and Tisma Pond because they do not comprise a demographic population (see below).

\section{Pairwise comparisons between populations}

Tamura \& Nei distance estimates were used to compute the distance matrix for the statistical analysis, as they are the closest measure available in ARLEQUIN to the model that best fits the data (TVM) based on the proposed hierarchy for models of molecular evolution described in MODELTEST version 3.06 (Posada \& Crandall 1998).

Pairwise comparisons of genetic distances based on both mtDNA haplotypes and microsatellite loci detected strong differences between the populations of the Midas cichlid from the different lakes as well as between the two morphologically distinct forms/species $A$. zaliosus and $A$. labiatus. A. zaliosus appeared as the genetically most distant species of the complex with the highest levels of differentiation from the rest of the lineages (Table 3). The population from Tisma Pond located at the Tipitapa River between L. Managua and L. Nicaragua was not significantly different from the samples from L. Managua, and both were subsequently grouped in further analyses.

For A. citrinellus within L. Nicaragua no genetic differentiation based on mtDNA or microsatellites was found between the two locations sampled, Isletas and Ometepe $(P>0.05)$, but both populations differed from the sample 


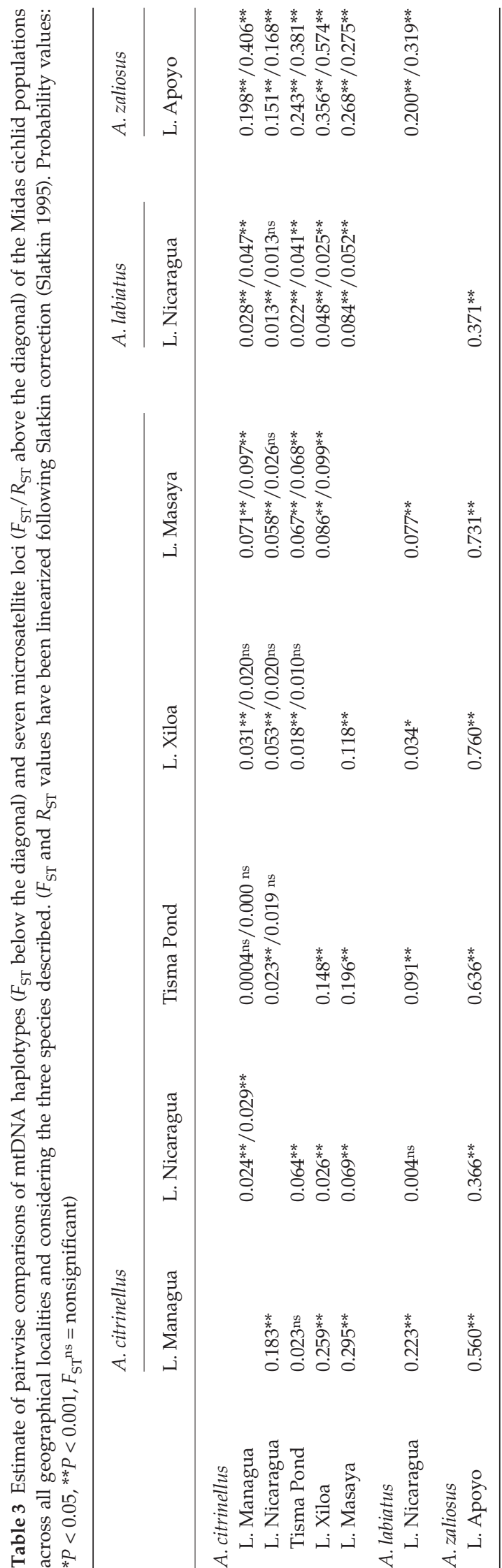

of A. labiatus from the Isletas locality based on microsatellites $F_{\mathrm{ST}}$.

Within L. Managua the two locations sampled showed significant differences in the mtDNA haplotypic structure $\left(F_{\mathrm{ST}}=0.101, P=0.009\right)$, although the microsatellite analyses failed to find any significant differentiation $(P>0.05)$. When the Tisma sample was included in the comparison, it appeared to be genetically indistinguishable from the sample from San Francisco Libre $(P>0.05$ both mtDNA and microsatellite analyses), but significantly different from the sample from Miraflores in the mt DNA haplotypic structure $\left(F_{\mathrm{ST}}=0.099, P<0.001\right)$ although not in the microsatellite analysis $(P>0.05)$.

The ranges for both $F$ - and $R_{\mathrm{ST}^{-}}$-statistics were similar, suggesting that the time scale of the divergence of the Midas cichlid complex is sufficiently recent that mutation plays a minor role and F-statistics is a valid tool for the analysis of microsatellite divergence (Table 3).

\section{Comparisons between trophic and colour morphs from sympatric populations}

A. citrinellus is a polychromatic species with two distinct described colour morphs. In the two big lakes and Tisma Pond gold and normal morphs were found in sympatry. Within the crater lakes only normal cryptic forms were found in our sampling, although in both L. Xiloa and L. Masaya gold morphs exist in deeper water (Barlow 1976; Meyer 1990a,b; McKaye et al. 2002). Comparisons of the two colour morphs from sympatric collections showed significant differences for L. Managua (S. Fco Libre-Tisma based on both nuclear and mitochondrial markers, and in Miraflores based on nuclear markers only) (Table 4). In L. Nicaragua, the two sympatric morphological types found in the Isletas (A. citrinellus and A. labiatus) were polychromatic (the sample of $A$. citrinellus from Ometepe included only normal forms). The colour morphs were in both localities genetically differentiated on the basis of nuclear neutral markers (Table 4).

Two different types of pharyngeal jaws have been described in A. citrinellus: papilliform and molariform. For both $A$. labiatus and $A$. zaliosus only papilliform pharyngeal jaws have been described previously in the literature (Meyer 1989, 1990a,b). All A. citrinellus individuals sampled in L. Managua, Tisma Pond and L. Masaya had papilliform pharyngeal jaws (see also Meyer 1990a). All A. citrinellus individuals collected in Ometepe in L. Nicaragua had molariform pharyngeal jaws. Among samples of A. citrinellus that were collected from L. Xiloá, L. Apoyo (A.zaliosus) and Isletas, L. Nicaragua both trophic morphs were found in sympatry. This study provides the first evidence of molariform pharyngeal jaws on fish from Lake Apoyo. In the comparison of the trophic groups within their sympatric distribution all comparisons were nonsignificant (Table 4). 


\begin{tabular}{|c|c|c|c|}
\hline & \multirow{2}{*}{$\begin{array}{l}\text { mtDNA } \\
F_{\mathrm{ST}}\end{array}$} & \multicolumn{2}{|c|}{ Microsatellites } \\
\hline & & $F_{\mathrm{ST}}$ & $R_{\mathrm{ST}}$ \\
\hline \multicolumn{4}{|l|}{ Between colour morphs } \\
\hline \multicolumn{4}{|l|}{ A. citrinellus } \\
\hline L. Managua, Miraflores & $0.049 \mathrm{~ns}$ & $0.001^{\mathrm{ns}}$ & $0.031^{*}$ \\
\hline L. Managua, S. Fco Libre - Tisma & $0.363^{* *}$ & $0.000^{\mathrm{ns}}$ & $0.020^{* *}$ \\
\hline L. Nicaragua, Isletas & $0.000 \mathrm{~ns}$ & $0.013^{*}$ & $0.000 \mathrm{~ns}$ \\
\hline \multicolumn{4}{|l|}{ A. labiatus } \\
\hline L. Nicaragua, Isletas & $0.003^{n s}$ & $0.010^{* *}$ & $0.000^{\mathrm{ns}}$ \\
\hline \multicolumn{4}{|l|}{ Between trophic morphs } \\
\hline \multicolumn{4}{|l|}{ A. citrinellus } \\
\hline L. Nicaragua, Isletas & $0.033^{\mathrm{ns}}$ & $0.000^{\mathrm{ns}}$ & $0.000^{\text {ns }}$ \\
\hline L. Xiloa & $0.000 \mathrm{~ns}$ & $0.000 \mathrm{~ns}$ & $0.000 \mathrm{~ns}$ \\
\hline \multicolumn{4}{|l|}{ A. zaliosus } \\
\hline L. Apoyo & $0.000 \mathrm{~ns}$ & $0.039 \mathrm{~ns}$ & $0.017 \mathrm{~ns}$ \\
\hline
\end{tabular}

Table 4 Estimate of pairwise $F_{\mathrm{ST}}$ and $R_{\mathrm{ST}}$ for all populations where two colour or trophic morphs coexist in sympathy $\left(F_{\mathrm{ST}}\right.$ and $R_{\mathrm{ST}}$ values have been linearized following Slatkin correction. Probability values: ${ }^{*} P<0.05,{ }^{* *} P<0.001$, ns $=$ nonsignificant $)$

\section{Discussion}

The Neotropical Midas cichlid species complex is ubiquitous in the Great Lakes Basin of Nicaragua, and comprises the largest biomass of any fish species in these lakes. The Midas cichlid has predominantly generalist habits and covers a wide range of ecological habitats. This pattern contrasts with the general trend observed in most cichlids from the African Great Lakes, where species are highly specialized and typically confined to discrete habitats and often extremely fine ecological niches (reviewed in Fryer \& Iles 1972). Neotropical cichlids are often associated with high levels of phenotypic plasticity and are generally believed to show decreased tendencies for speciation, at least by comparison to the 'explosively' speciating African cichlids (Kornfield et al. 1982; Meyer 1987, 1990b). This study documents large amounts of genetic structuring among populations of the Midas cichlid species complex in the lakes of Nicaragua, which might call the previous hypotheses into question.

In agreement with earlier genetic and morphometric studies (Wilson et al. 2000; McKaye et al. 2002; Klingenberg et al. 2003), this study finds substantial phenotypic as well as genetic differentiation between populations of the Midas cichlid in the lakes of Nicaragua (Fig. 3, Table 3), corroborating expectations from traditional models of divergence among allopatric populations.

\section{Historical context and age estimation}

The origin of the Great Lakes Basin of Nicaragua is due to tectonic activity and has been dated to the early Quaternary (<1 Mya) (Riedel 1972; Bussing 1976). Originally the two big lakes, L. Managua and L. Nicaragua, together with the small L. Xiloá, were part of a single lake basin, the 'Great Nicaraguan Lake' (Villa 1968). Stratigraphic evidence shows that during the Pleistocene the level of the water was $20 \mathrm{~m}$ higher than at present (Hayes 1899). The first arrival of freshwater fishes to the lakes is dated to around 500000 years ago (Bussing 1976), when these three lakes still formed a single water body. The faunal correspondence among the three lakes observed agrees with the geological evidence (Villa 1968). In the late Pleistocene the Great Nicaraguan Lake opened to the Atlantic Ocean through the San Juan River, and the water level dropped. This resulted in the separation of the initial lake into two basins, L. Nicaragua and a basin including L. Managua and L. Xiloá (Villa 1976a,b). More recently (not dated), L. Xiloá and L. Managua also separated into two different lakes (Villa 1968). The two large lakes remained connected by the Tipitapa River, a partially subterranean river that flows from L. Managua into L. Nicaragua, which might have constituted somewhat of a barrier to the dispersal of fish (Villa 1976a,b).

From our population genetic analyses we estimate that the first rapid increase of the population sizes of the Midas cichlid species complex in the Nicaraguan lakes occurred around 91000 years ago in L. Managua, and that from this population L. Nicaragua was colonized (the main population expansion is estimated to have occurred around 74000 ya) (Table 2). These two populations are genetically distinct due to the isolation of the two lakes, but still many mitochondrial haplotypes are shared supporting the hypothesis of a common origin (Figs 3 and 4). Occasional overflows of L. Managua into L. Nicaragua have been reported (Villa 1976a,b), and a permanent pond along the Tipitapa River contains a stable A. citrinellus population that is indistinguishable genetically from that from $\mathrm{L}$. Managua (Table 3).

The crater lake populations were seeded from the populations of the big lakes. The fauna of L. Xiloá originated from L. Managua and the main population expansion is 
estimated to have occurred around 66000 ya. The fossil record indicates that the original fauna of L. Xiloá was more diverse than it is nowadays, but the high concentration of salts in its water caused the disappearance of some species, and the adaptation to the new conditions of some others (Villa 1968). Two endemic species have been found in L. Xiloá (a fish and a crustacean), and Stauffer \& McKaye (2002) have proposed that three new species of the $A$. citrinellus complex might have differentiated within the lake. Our study found clear genetic differentiation of the Midas cichlid in L. Xiloá from the populations in the rest of the lakes, although our sample does not suggest further substructuring within this lake. Interestingly, as both colour morphs and both pharyngeal jaw morphs of A. citrinellus are found in L. Xiloá (Meyer 1990a) as well as some of the other crater lakes, these polymorphisms and probably incipient species arose not only sympatrically but in parallel in these different crater lakes (see also Wilson et al. 2000).

The origin of the seeding cichlid faunas of L. Apoyo and L. Masaya is largely unknown, but human introduction has been proposed (Astorqui 1967). Our study suggests that both lakes might have been seeded with fish from L. Nicaragua (Fig. 3) geographically closest to both of them. The Midas cichlid population in L. Masaya is not monophyletic (Fig. 3), and has experienced either several introductions or a large and already diverse founder population was introduced. On the other hand, the Midas cichlid population from L. Apoyo, specifically A. zaliosus, appears to be monophyletic, pointing to one single colonization event with a small number of seeding individuals for that crater lake (Fig. 3). All genetic diversity that is contained in our L. Apoyo sample and the origin of at least one new species (A. zaliosus) probably arose within this small crater lake since its recent geological origin of less than 23000 ya (Riedel 1972; Bice 1985).

\section{Origin of two new species through sympatric speciation}

Previous morphometric studies (Barlow \& Munsey 1976; Meyer 1990a,b; McKaye et al. 2002; Klingenberg et al. 2003) have shown that closely related forms of the Midas cichlid complex with marked ecological specializations coexist in some areas in Nicaragua and also in the three small crater lakes, suggesting that sympatric differentiation might be ongoing. This study provides the first genetic evidence for the genetic differentiation between the three species of the Midas cichlid species complex.

A. labiatus, a species with morphological adaptations to feed on invertebrates between crannies, such as an elongated head and fleshy lips, occurs sympatrically with the generalist $A$. citrinellus in Isletas, L. Nicaragua. Both morphometric (Klingenberg et al. 2003) and molecular data show significant differences between these two species.
Although mating experiments between these two species have yet not been conducted, the extent of the genetic differences found here supports the assignment of $A$. citrinellus and $A$. labiatus as distinct biological species. However, these species are young, and a large number of mtDNA haplotypes are still shared between those two evolutionary lineages (Fig. 3).

Fleshy-lipped forms have repeatedly evolved in many different cichlid radiations both in the Neotropics and the Great East African Lakes (Stiassny \& Meyer 1999). The evolution of fleshy lips is an example for the type of morphological innovation that results in ecological differences that might lead to the evolution of novel species. In L. Apoyo, a small lake $\left(21.2 \mathrm{~km}^{2}\right)$ of recent volcanic origin, two morphologically distinct forms have been previously identified, an elongated species inhabiting the limnetic niche, A. zaliosus, and the typical deeper-bodied A. citrinellus species inhabiting the benthic niche (Barlow \& Munsey 1976; Klingenberg et al. 2003). Although both species have been found in this small crater lake previously (Barlow \& Munsey 1976; A. Meyer and T. Hrbek, unpublished data), all the individuals collected for this study from this lake were morphologically monomorphic, but differed as determined by a morphometric analyses of body shape from $A$. citrinellus from other populations (Klingenberg et al. 2003). Therefore, all specimens collected by us from L. Apoyo for this study are likely to be A. zaliosus. Rather than to presume that $A$. zaliosus previously had a wider geographical distribution and went extinct in all other localities later, we believe strongly that $A$. zaliosus arose in sympatry from an $A$. citrinellus ancestral lineage within L. Apoyo. The mitochondrial DNA analyses (Fig. 3, Table 3) show that all A. zaliosus specimens from L. Apoyo are genetically closely related (only eight haplotypes differing by maximally one mutation among the 50 specimens were found), suggesting that this species is very young and that the founding population for this new group might have been small. The most probable mechanism for the observed differences between these two species that differ in their ecology (benthic vs. limnetic habitat and associated deep vs. shallow bodies) is diversification of sympatric competing populations that are specialized to live in different habitats through ecological speciation. L. Apoyo is oligotrophic compared to the other Nicaraguan crater lakes (Barlow et al. 1976), and trophic specializations and associated habitat shifts might be necessary in this environment. The occurrence of differentiation between benthic and limnetic forms within species is a common phenomenon observed not only in some populations of A. citrinellus (Meyer 1990ab), but is known from various populations of a range of other species in freshwater lakes (Schluter 1993; Lu \& Bernatchez 1999; Rundle et al. 2000; see review by Smith \& Skúlason 1996) and is also known from some African cichlids (Schliewen et al. 1994). Furthermore, 
assortative mating between these two species has been observed in L. Apoyo (Barlow \& Munsey 1976).

\section{Sympatric speciation: ecological specialization vs. sexual selection}

Ecological adaptation appears to be one of the main mechanisms of population differentiation and speciation in the Midas cichlid complex. The adaptation of A. labiatus to feed on invertebrates in crannies in L. Nicaragua and the adaptation to live in open waters of $A$. zaliosus in L. Apoyo (similarly to the limnetic morphs of $A$. citrinellus) resulted in the genetic isolation of these forms from the generalist $A$. citrinellus producing new species with stable reproductive barriers. However, although the Midas cichlid is known to have distinct trophic morphs (papilliform and molariform pharyngeal jaws) that are ecologically specialized on soft and hard preys, respectively, with known ecological effects (Meyer 1989, 1990a), our molecular markers could not find genetic difference between the trophic morphs with this species (Table 4).

There are several explanations for this result. All species of the Midas cichlid species complex start life with papilliform pharyngeal jaws and, as individuals reach about $10 \mathrm{~cm}$ in length (Meyer 1990a), some of them begin to replace their papilliform teeth on their pharyngeal jaws with molariform teeth (Meyer 1990a,b). The abundance of molariform fish in a population seems to be correlated with the abundance of hard-shelled prey (snails) in the environment (Meyer 1990a). Distinct pharyngeal jaw polymorphisms have been identified in several species of cichlids (Greenwood 1965; Kornfield et al. 1982; Hoogerhoud 1983; Kornfield \& Taylor 1983; Meyer 1993a) and, at least in some of these species, a large environmental component to the pharyngeal jaw phenotype has been suggested. The ontogenetic shift in $A$. citrinellus from a papilliform to molariform pharyngeal jaw dentition might be to some extent environmentally induced (Meyer 1990a). Therefore, these ecologically important morphological differences might be phenotypically plastic, which would explain the lack of genetic differences between these morphs. However, we cannot rule out, as yet, a genetic basis for the differences in the pharyngeal jaw dentition. We are currently conducting both breeding as well as common garden experiments to determine the extent of the genetic determination of this phenotypic difference in $A$. citrinellus.

We find some indications of genetic differentiation between the colour morphs (Table 4). Because it is known, furthermore, that assortative mating is very strong in these fish, these data support the hypothesis that sexual selection initially might cause speciation without the requirement of a concomitant ecological differentiation (e.g. reviews in Panhuis et al. 2001; Via 2001). Variation in colouration is extensive within the adaptive radiations of cichlid in East African lakes, and assortative mating on the basis of col- ouration has been documented in several species including the Midas cichlid species complex (e.g. McKaye et al. 1984; Seehausen et al. 1998). In African cichlids sexual selection is claimed to be one of the key factors promoting diversification (Meyer 1993b; Seehausen et al. 1998). However, empirical data in support of this hypothesis is hard to obtain.

All fish of the Midas cichlid start out life with a normal cryptic colouration, and during ontogeny some of them experience a colour metamorphosis, lose their melanophores and turn gold (Barlow 1976). In most populations of the Midas cichlid around $8 \%$ of mature adults are brightly (gold) coloured (Barlow 1976). The two colour morphs show a strong tendency to mate assortatively with respect to colour both in the field and in the laboratory (Barlow \& Rogers 1978; McKaye 1980, 1986). As fish from each population are related more closely to each other than to fish outside the lake, this system provides an ideal situation for testing the hypothesis of ongoing sympatric speciation in parallel settings via sexual selection. A previous study already found tentative evidence in favour of incipient sympatric speciation on the basis of colouration in the Midas cichlid based on a smaller sample of $A$. citrinellus than were included in this study (Wilson et al. 2000). Here we report on a more extensive sampling of the populations of Midas cichlid in Nicaragua, including one more polychromatic species from the complex and base the population genetic analyses on a larger sample of molecular markers. This study corroborates the hypothesis of the importance of sexual selection in these cichlids by discovering significant structuring of populations on the basis of colouration in all polychromatic populations.

The Midas cichlid has differentiated into distinct ecological types with morphological adaptations such as big lips and benthic and limnetic body forms that feed on different diets and inhabit different areas of the lakes forming three recognized species (A. citrinellus, A. labiatus and A. zaliosus). A more recent diversification might be happening within two of the named species in the complex due to sexual selection by assortative mating on the basis of the colour polymorphism. These patterns are consistent with those proposed for the radiation of cichlids in the main African Lakes Tanganyika and Malawi, where major lineages are trophically divergent and more recent lineages are differentiated based largely on colouration differences (Meyer 1993b; Sturmbauer 1998; Stiassny \& Meyer 1999; Danley \& Kocher 2002). Contemporary sympatric speciation in the African Great Lakes might be caused by sexual selection, accompanied by minor or no ecological differences (Mayr 1984; Baric et al. 2002).

\section{Patterns of cichlid evolution}

Although major differences in the patterns of evolution have been proposed for East African and Neotropical 
cichlids (Kornfield et al. 1982; Meyer 1987), both trophic specialization (and hence ecological speciation) and sexual selection seem to be two of the main mechanisms promoting differentiation and speciation in cichlids. Endemism, trophic adaptations and assortative mating are common phenomena in the Midas cichlid complex, resembling the larger scale evolutionary scenario found in the adaptive radiation of East African cichlids. The evolution of cichlids in the Nicaraguan Lakes has been, however, conservative compared with the explosive morphological, ecological and behavioural diversification of cichlids in East African Lakes of similarly recent origin (i.e. 10 cichlid species are found in L. Nicaragua vs. $500+$ cichlid species in Lake Victoria that might be even younger than L. Nicaragua: see Meyer et al. 1990; Verheyen et al. 2003). In contrast, the levels of genetic divergence in the Midas cichlid complex (three species, 150 haplotypes, max. genetic distance $=11$ mutations) are very similar to those observed in some East African lakes of different size and age (i.e. L. Victoria: $500+$ species, 41 haplotypes, max. genetic distance $=10$ mutations; L. Kivu: 15 haplochromine species, 41 haplotypes, max. genetic distance = nine mutations; Verheyen et al. 2003). This supports the idea that genetic divergence is not a sufficient metric of morphological diversification and species richness (Meyer et al. 1990; Sturmbauer \& Meyer 1992; Verheyen et al. 2003), but rather that even among cichlids there are differences in the rates of morphological diversification and speciation.

Two factors might be the key reasons for the differences between the explosive morphological differentiation of the cichlid flock in a recent East African lake, such as the haplochromine superflock of L. Victoria, and the evolution of cichlids in the Nicaraguan lakes. First, generally speaking there is a correlation between the size of a lake and the size of a species flock, because the main African cichlid radiations took place in some of the larger lakes of the rift valley (L. Tanganyika $=32000 \mathrm{~km}^{2}$, L. Malawi $=26900 \mathrm{~km}^{2}$ ). Lake Victoria (L. Victoria $=68000 \mathrm{~km}^{2}$ ) and the other two large African lakes have a great variety of environments and a more complex fish community than the smaller Nicaraguan lakes $\left(\right.$ L. Nicaragua $=8150 \mathrm{~km}^{2} ;$ L. Managua $\left.=1040 \mathrm{~km}^{2}\right)$. The size of the fauna of the Nicaraguan lakes, however, is comparable to the fauna of similarly sized lakes in the African rift valley. L. Albert, a rift-valley lake with similar size, age and depth to L. Nicaragua (age $=500000$ years; size $=$ $6800 \mathrm{~km}^{2}$; mean depth $=25 \mathrm{~m}$ ), contains a similar number of fish species (45 vs. 40 species) and the same number of cichlid species (10). Secondly, the location of L. Victoria in the African rift valley, which connected it in the recent past to a complex set of very old and deep lakes that have acted as reservoirs of cichlid species over the years (Salzburger et al. 2002; Verheyen et al. 2003), has favoured the colonization of L. Victoria by possibly already lake-adapted ancestral cichlid lineages that were already somewhat diversified
(Verheyen et al. 2003). In contrast, the Nicaraguan lakes are an exceptional environment in the Neotropics, an area dominated by large rivers, and their fauna is derived from riverine fish. Such an ecological setting might be more prone to preserve ancestral characters (Kullander 1998).

The evolution of the Midas cichlid species complex in Nicaragua provides empirical evidence for some of the previously presumed general patterns of cichlid evolution in lacustrine environments. Both allopatric differentiation of geographically distant populations as a by-product of isolation and, more interestingly, sympatric differentiation in parallel due to separation of colour and ecological morphs in sympatric populations might be driving the diversification and speciation of this system. Ecological specialization and adaptation to local environments is found in the Midas cichlid complex; however, sexual selection through assortative mating also appears to initiate the differentiation of at least some populations in this system. Further studies of the ecology and behaviour of these species might lead to a more comprehensive understanding of the interactions of the two complementary selective forces promoting diversification in this cichlid system.

The Midas cichlid in Nicaragua appears to be an excellent model system for the study of early stages of adaptation and speciation in a cichlid lacustrine species flock. The three crater lakes of Nicaragua, in particular, provide an unparalleled opportunity for the study of the incipient stages of sympatric speciation in parallel evolutionary settings, comparable only to the repeated parallel speciation events of sticklebacks in the postglacial lakes in British Columbia (reviewed in Schluter 2000). Unfortunately, through the recent introduction of African tilapiine cichlids this natural laboratory of speciation has become threatened (McCrary et al. 2001) and is in urgent need of conservation measures.

\section{Acknowledgements}

We thank MARENA in Nicaragua for providing all permits for field collection, D. Valerio and S. Vilches for assistance in the field and $\mathrm{H}$. Fischer and U. Topel for assistance in the laboratory. We also thank Walter Salzburger, Sergey Gavrilets and one anonymous referee for valuable comments on the manuscript. This study was supported by grants of the Fond der Chemischen Industrie, and the University of Konstanz to AM, Deutsche Forschungsgemeinschaft to MB and AM, and by Consejería de Educación y Cultura del Principado de Asturias, Plan de Investigación Desarrollo Tecnológico e Innovación de Asturias 2001-04 to MB.

\section{References}

Astorqui I (1967) Origen de los peces de los lagos. Revista Conservadora, 16, 66-68.

Balloux F, Lugon-Moulin N (2002) The estimation of population differentiation with microsatellite markers. Molecular Ecology, 11, 155-165. 
Baric S, Salzburger W, Sturmbauer C (2002) Phylogeography and evolution of the Tanganyikan cichlid genus Tropheus based upon mitochondrial DNA sequences. Journal of Molecular Evolution, 55, 1-15.

Barlow GW (1976) The Midas Cichlid in Nicaragua. In: Investigations of the Ichthyofauna of Nicaraguan Lakes (ed. Thorson TB), pp. 333-358. University of Nebraska Press, Lincoln, NB.

Barlow GW, Baylis JR, Roberts DA (1976) Chemical analyses of some crater lakes in relation to adjacent Lake Nicaragua. In: Investigations of the Ichthyofauna of Nicaraguan Lakes (ed. Thorson TB), pp. 17-20. University of Nebraska Press, Lincoln, NB.

Barlow GW, Munsey JW (1976) The red devil-Midas-arrow cichlid species complex in Nicaragua. In: Investigations of the Ichthyofauna of Nicaraguan Lakes (ed. Thorson TB), pp. 359-369. University of Nebraska Press, Lincoln, NB.

Barlow GW, Rogers W (1978) Female Midas cichlid's choice of mate in relation to parents' and own color. Biology of Behavior, 3, 137-145.

Barraclough TG, Vogler AP (2000) Detecting the geographical pattern of speciation from the species-level phylogenies. American Naturalist, 155, 419-434.

Bice D (1985) Quaternary volcanic stratigraphy of Managua, Nicaragua. Bulletin of the Geological Society of America, 96, 553-566.

Bruford MW, Hanotte O, Brookfield JFY, Burke T (1998) Multilocus ands single-locus DNA fingerprinting. In: Molecular Genetic Analysis of Populations (ed. Hoelzel AR), pp. 283-336. Oxford University Press, New York.

Bussing WA (1976) Geographic distribution of the San Juan Ichthyofauna of Central America with remarks on its origin and ecology. In: Investigations of the Ichthyofauna of Nicaraguan Lakes (ed. Thorson TB), pp. 157-175. University of Nebraska Press, Lincoln, NB.

Danley PD, Kocher TD (2002) Speciation in rapidly diverging systems: lessons from Lake Malawi. Molecular Ecology, 10, 10751086.

Dieckmann U, Doebeli M (1999) On the origin of species by sympatric speciation. Nature, 400, 354-357.

Doebeli M, Dieckmann U (2000) Evolutionary branching and sympatric speciation caused by different types of ecological interactions. American Naturalist, 1556, S77-S101.

Donaldson KA, Wilson RR (1999) Amphi-Panamic geminates of snook (Percoidei: Centropomidae) provide a calibration of the divergence rate in the mitochondrial DNA control region of fishes. Molecular Phylogenetics and Evolution, 13, 208-213.

Feder JL (1998) The apple margot fly, Rhagoletis pomonella: flies in the face of conventional wisdom about speciation. In: Endless Forms: Species and Speciation (eds Howard DJ, Berlocher SH), pp. 130-144. Oxford University Press, New York.

Fryer G, Iles TD (1972) The Cichlid Fishes of the Great Lakes of Africa. Olyver \& Boyd, London.

Gavrilets S, Waxman D (2002) Sympatric speciation by sexual conflict. Proceedings of the National Academy of Sciences USA, 99, 10533-110538.

Greenwood PH (1965) Environmental effects on the pharyngeal mil of a cichlid fish, Astatoreochromis alluadudi, and their taxonomic implications. Proceedings of the Linnean Society of London, 176, 1-10.

Guo S, Thompson E (1992) Performing the exact test of HardyWeinberg proportion of multiple alleles. Biometrics, 48, 361-372.

Hayes CW (1899) Physiography and geology of the region adjacent to the Nicaraguan Canal route. Bulletin of the Geological Society of America, 10, 285-348.
Higashi M, Takimoto G, Yamamura N (1999) Sympatric speciation by sexual selection. Nature, $402,523-526$.

Hoogerhoud RJC (1983) The ecological differentiation of two closely resembling Haplochromis species from Lake Victoria (H. iris and H. hiatus). Netherlands Journal of Zoology, 33, 283-305.

Hori M (1993) Frequency-dependent natural selection in the handedness of scale-eating cichlid fish. Science, 260, 216-219.

Huelsenbeck JP, Crandall KA (1997) Phylogeny estimation and hypothesis testing using maximum likelihood. Annual Review of Ecology and Systematics, 28, 437-466.

Huysseune A, Rüber L, Verheyen E (1999) A single tooth replacement pattern generates diversity in cichlids of the tribe Eretmodini, endemic to Lake Tanganyika (Teleostei, Cichlidae). Belgian Journal of Zoology, 129, 157-174.

Kellog KA, Markert JA, Stauffer JRJ, Kocher TD (1995) Microsatellite variation demonstrates multiple paternity in lekking cichlid fishes from Lake Malawi, Africa. Proceedings of the Royal Society of London Series B, 260, 79-84.

Kirkpatrick M (2000) Fish found in flagrante delicto. Nature, 408, 298-299.

Klingenberg CP, Barluenga M, Meyer A (2003) Body shape variation in cichlid fishes of the Amphilophus citrinellus species complex. Biological Journal of the Linnean Society, 80, 397-408.

Knight ME, Turner GF (1999) Reproductive isolation among closely related Lake Malawi cichlids: can males recognize conspecific females by visual cues? Animal Behavior, 58, 761768.

Kocher TD, Thomas WK, Meyer A et al. (1989) Dynamics of mitochondrial DNA evolution in animals: amplification and sequencing with conserved primers. Proceedings of the National Academy of Sciences USA, 86, 6196-6200.

Kondrashov AS, Kondrashov FA (1999) Interactions among quantitative traits in the course of sympatric speciation. Nature, 400 , 351-354.

Kondrashov AS, Yampolsky LYu, Shabalina SA (1998) On the sympatric origin of species by means of natural selection. In: Endless Forms: Species and Speciation (eds Howard DJ, Berlocher SH), pp. 90-98. Oxford University Press, New York.

Kornfield IL, Smith PF (2000) African cichlid fishes: model systems for evolutionary biology. Annual Review of Ecology and Systematics, 31, 163-196.

Kornfield IL, Smith DC, Gagnon PS, Taylor JN (1982) The cichlid fish of Cuatro Cienagas, Mexico: direct evidence of conspecificity among distinct trophic morphs. Evolution, 36, 658-664.

Kornfield IL, Taylor JN (1983) A new species of polymorphic fish, Cichlasoma minkleyi from Cuatro Cienagas, Mexico (Tleostei: Cichlidae). Proceedings of the Biological Society of Washington, 96, 253-269.

Kosswig C (1947) Selective mating as a factor for speciation in cichlid fish of East African lakes. Nature, 159, 604-605.

Kullander SO (1998) A phylogeny and classification of the South American Cichlidae (Teleostei: Perciformes). In: Phylogeny and Classification of Neotropical Fishes (eds Malabara LR, Reis RE, Vari RP, Lucena ZM, Lucena CAS), pp. 461-498. Edipucrs, Porto Alegre, Brazil.

Liem KF (1973) Evolutionary strategies and morphological innovations: cichlid pharyngeal jaws. Systematic Zoology, 22, 425-441.

Losos J, Leal M, Glor RE et al. (2003) Niche lability in the evolution of a Caribean lizard community. Nature, 424, 542-545.

Lowe-McConnell R (1991) Ecology of cichlids in South American and African waters, excluding the African Great Lakes. In: 
Cichlid Fishes: Behavior, Ecology and Evolution (ed. Keenleyside MHA). Chapman \& Hall, London.

Lu G, Bernatchez L (1999) Correlated trophic specialization and genetic divergence in sympatric lake whitefish ecotypes (Coregonus clupeaformis): support for the ecological specialization hypothesis. Evolution, 53, 1491-1505.

Mayr E (1963) Animal Species and Evolution. Harvard University Press, Cambridge.

Mayr E (1984) Evolution of fish species flocks: a commentary. In: Evolution of Fish Species Flocks (eds Echelle AA, Kornfield IRV), pp. 3-11. University of Maine at Orono Press, Orono, Maine.

McCrary J, van der Berghe E, McKaye KR, López Pérez L (2001) El cultivo de tilapias: una amenaza a las especies ícitcas nativas en Nicaragua. Encuentro, 58, 9-19.

McKaye KR (1980) Seasonality in habitat selection by the gold color morph of Cichlasoma citrinellum and its relevance to sympatric speciation in the family Cichlidae. Environmental Biology of Fishes, 5, 75-78.

McKaye KR (1986) Mate choice and size assortative pairing by the cichlid fishes of Lake Jiloa, Nicaragua. Journal of Fish Biology, 29, 135-150.

McKaye KR, Barlow GW (1976) Competition between color morphs of the Midas cichlid, Cichlasoma citrinellum, in lake Xiloá, Nicaragua. In: Investigations of the Ichthyofauna of Nicaraguan Lakes (ed. Thorson TB), pp. 465-475. University of Nebraska Press, Lincoln, NB.

McKaye KR, Kocher TD, Reinthal P, Harrison H, Kornfield I (1984) Genetic evidence for allopatric and sympatric differentiation among color morphs of a Lake Malawi cichlid fish. Evolution, 38, 215-219.

McKaye KR, Stauffer JR, van der Berghe EP et al. (2002) Behavioral, morphological and genetic evidence of divergence of the Midas cichlid species complex in two Nicaraguan crater lakes. Cuadernos de Investigación de la Universidad Centroamericana, 12, $19-47$.

Meyer A (1987) Phenotypic plasticity and heterochrony in Cichlasoma managuense (Pisces, Cichlidae) and their implications for speciation in cichlid fishes. Evolution, 41, 1357-1369.

Meyer A (1989) Cost of morphological specialization: feeding performance of the two morphs in the trophically polymorphic cichlid fish, Cichlasoma citrinellum. Oecologia, 80, 431-436.

Meyer A (1990a) Ecological and evolutionary consecuences of the trophic polymorphism in Cichlasoma citrinellum (Pisces: Cichlidae). Biological Journal of the Linnean Society, 39, 279-299.

Meyer A (1990b) Morphometrics and allometry in the trophically polymorphic cichlid fish, Cichlasoma citrinellum: alternative adaptations and ontogenetic changes in shape. Journal of Zoo$\log y, 221,237-260$.

Meyer A (1993a) Trophic polymorphisms in cichlid fish: do they represent intermediate steps during sympatric speciation and explain their rapid adaptive radiation? In: Trends in Ichthyology: an International Perspective (eds Schröder JH, Bauer J, Schartl M), pp. 257-266. Blackwell Scientific Publications, Oxford.

Meyer A (1993b) Phylogenetic relationships and evolutionary processes in East African cichlid fishes. Trends in Ecology and Systematics, 8, 279-284.

Meyer A, Kocher T, Basasibwaki P, Wilson A (1990) Monophyletic origin of Lake Victoria fishes suggested by mitochondrial DNA sequences. Nature, 347, 550-553.

Meyer A, Morrissey JM, Schartl M (1994) Recurrent origin of a sexually selected trait in Xiphophorus fishes inferred from a molecular phylogeny. Nature, 368, 539-542.
Noack K, Wilson AB, Meyer A (2000) Broad taxonomic applicability of microsatellites developed for the polymorphic Neotropical cichlid (Amphilophus citrinellus). Animal Genetics, 31, 151-152.

Page DM, Holmes EC (1998) Molecular Evolution: a Phylogenetic Approach. Blackwell Sciences, Oxford.

Panhuis TM, Butlin R, Zuk M, Tregenza T (2001) Sexual selection and speciation. Trends in Ecology and Evolution, 16, 364-371.

Posada D (1999) Collapse, Version 1.1. Department of Zoology, Brigham Young University, Salt Lake City, UT.

Posada D, Crandall KA (1998) modeltest: testing the model of DNA substitution. Bioinformatics, 14, 817-818.

Rice WR (1989) Analyzing tables of statistical tests. Evolution, 43, 223-225.

Riedel D (1972) Die Genesis der nicaraguenischen Grabenseen (Teil I) und des mesoamerikanischen Isthmus (Teil II) aus der Sicht des Fischereibiologen. Archiv Hydrobiologica, 70, 82-107.

Rossiter A (1995) The cichlid fish assemblage of Lake Tanganyika: ecology, behavior and evolution of its species flocks. In: Advances in Ecological Research (eds Begon M, Fitter AH), pp. 401. Academic Press, Boston.

Rüber L, Verheyen E, Meyer A (1999) Replicated evolution of trophic specializations in an endemic cichlid fish lineage from Lake Tanganyika. Proceedings of the National Academy of Sciences USA, 96, 10230-10235.

Rundle HD, Nagel L, Boughman JW, Schluter D (2000) Natural selection and parallel speciation in sympatric sticklebacks. Science, 287, 306-308.

Salzburger W, Meyer A, Baric S, Verheyen E, Sturmbauer C (2002) Phylogeny of the Lake Tanganyika cichlid species flock and its relationship to the Central- and East-African Haplochromine cichlid fish faunas. Systematic Biology, 51, 113-135.

Schliewen UK, Tautz D, Paabo S (1994) Sympatric speciation suggested by monophyly of crater lake cichlids. Nature, 368 , 629-632.

Schluter D (1993) Adaptive radiation in sticklebacks: size, shape, and habitat use efficiency. Ecology, 74, 699-709.

Schluter D (1994) Experimental evidence that competition promotes divergence in adaptive radiation. Science, 266, 798-801.

Schluter D (2000) The Ecology of Adaptive Radfiation. Oxford University Press, New York.

Schneider S, Excoffier L (1999) Estimation of past demographic parameters from the distribution of pairwise differences when the mutation rates vary among sites: application to human mitochondrial DNA. Genetics, 152, 1079-1089.

Schneider S, Roessli D, Excoffier L (2000) ARLEQUIN, Version 2.000: a Software for Genetic Data Analysis. Genetics and Biometry Laboratory, University of Geneva, Switzerland.

Seehausen O, Koetsier E, Schneider MV (2003) Nuclear markers reveal unexpected genetic variation and Congolese-Nilotic origin of the Lake Victoria cichlid species flock. Proceedings of the Royal Society of London Series B, 270, 129-137.

Seehausen O, van Alphen JJM (1999) Can sympatric speciation by disruptive sexual selection explain rapid evolution of cichlid diversity in Lake Victoria? Ecology Letters, 2, 262-271.

Seehausen O, van Alphen JJM, Witte F (1997) Cichlid fish diversity threatened by eutrophication that curbs sexual selection. Science, 277, 1808-1811.

Seehausen O, Witte F, van Alphen JJM, Bouton N (1998) Direct mate choice maintains diversity in among sympatric cichlids in Lake Victoria. Journal of Fish Biology, 53, 37-55.

Slatkin M (1995) A measure of population subdivision based on microsatellite allele frequencies. Genetics, 139, 457-462. 
Smith TB, Skúlason S (1996) Evolutionary significance of resource polymorphisms in fishes, amphibians, and birds. Annual Review of Ecology and Systematics, 27, 111-133.

Stauffer JR, McKaye KR (2002) Descriptions of three new species of cichlid fishes (Teleostei: Cichlidae) from Lake Xiloá, Nicaragua. Cuadernos de Investigación de la Universidad Centroamericana, 12, $1-18$.

Stiassny MLJ (1981) Phylogenetic versus convergent relationship between piscivorous cichlid fishes from Lakes Malawi and Tanganyika. Bulletin of the of the British Museum of Natural History and Zoology, 40, 67-101.

Stiassny MLJ, Meyer A (1999) Cichlids of the African Rift Lakes. Scientific American, February, 44-49.

Streelman JT, Danley PD (2003) The stages of vertebrate evolutionary radiation. Trends in Ecology and Evolution, 18, 126-131.

Sturmbauer C (1998) Explosive speciation in cichlid fishes of the African Great Lakes: a dynamic model of adaptive radiation. Journal of Fish Biology, 53, 18-36.

Sturmbauer C, Baric S, Salzburger W, Rüber L, Verheyen E (2001) Lake level fluctuations synchronize genetic divergences of cichlid fishes in African lakes. Molecular Biology and Evolution, 18, 144-154.

Sturmbauer C, Meyer A (1992) Genetic divergence speciation and morphological stasis in a lineage of African cichlid fishes. Nature, 358, 578-581.

Swofford DL (2002) PAUP*. Phylogenetic Analysis Using Parsimony (and Other Methods). Sinauer Associates, Sunderland, MA.

GF. Burrows MT (1995) A model of sympatric speciation by sexual selection. Proceedings of the Royal Society of London Series B, 260, 287-292.

Van Doorn GS, Luttikhuizen P, Weissing FJ (2001) Sexual selection at the protein level drives the extraordinary divergence of sex-related genes during sympatric speciation. Proceedings of the Royal Society of London Series B, 268, 2155-2161.
Verheyen E, Salzburger W, Snoeks J, Meyer A (2003) The origin of the superflock of cichlid fishes from Lake Victoria, East Africa. Science, 300, 325-329.

Via S (2001) Sympatric speciation in animals: the ugly duckling grows up. Trends in Ecology and Evolution, 16, 381-390.

Villa J (1968) Una teoría sobre el origen de los peces de Xiloá. Encuentro: Revista de la Universidad Centroamericana, 1, 202-214.

Villa J (1976a) Some speculations about 'The Great Nicaraguan Lake'. In: Investigations of the Ichthyofauna of Nicaraguan Lakes (ed. Thorson TB), pp. 191-196. University of Nebraska Press, Lincoln, NB.

Villa J (1976b) Peces Nicaragüenses de Agua Dulce. Fondo de Promoción Cultural, Banco de América, Managua.

Weir BS, Cockerham CC (1984) Estimating F-statistics for the analysis of population structure. Evolution, 38, 1358-1370.

Wilson AB, Noack K, Meyer A (2000) Incipient speciation in sympatric Nicaraguan crater lake cihclid fishes: sexual selection vs. ecological diversification. Proceedings of the Royal Society of London Series B, 267, 2133-2141.

Zardoya R, Vollmer D, Craddock C, Streelman TKS, Meyer A (1996) Evolutionary conservation of microsatellite flanking regions and the phylogeny of cichlid fishes (Pisces: Perciformes). Proceedings of the Royal Society of London Series B, 263, 1611-1618.

Zardoya R, Doadrio I (1999) Molecular evidence on the evolutionary and biogeographical patterns of European cyprinids. Journal of Molecular Evolution, 49, 227-237.

Marta Barluenga is a postdoctoral fellow interested in the origin of adaptive radiations. Axel Meyer is an evolutionary geneticist interested in the ecological, developmental and genomic aspects of speciation. 